\title{
Relação com o saber na aprendizagem matemática: uma contribuição para a reflexão didática sobre as práticas educativas
}

\author{
Veleida Anahi da Silva
}

Universidade Federal de Sergipe, Departamento de Educação e Núcleo de Pós-Graduação em Educação

Grupo de Pesquisa Educação e Contemporaneidade

Hoje em dia, o Brasil consegue matricular quase todas as crianças $(97 \%)$ no ensino fundamental. Todavia, uma sociedade moderna e democrática não se limita a acolher todos os jovens na escola, ela tenta levar todos ao próprio saber. Desse ponto de vista, a situação de nosso país não pode ser considerada satisfatória. Segundo o Ministério da Educação (MEC), em 2003, 51,6\% dos alunos da $4^{\mathrm{a}}$ série não tinham adquirido os conhecimentos matemáticos apropriados a essa faixa de escolarização e estavam em um estado "crítico" ou "muito crítico" (Brasil, 2004). A situação estava ainda pior na $8^{\mathrm{a}}$ série $(57,1 \%)$ e no $3^{\circ}$ ano do ensino médio (68,8\%). Além disso, parece que a situação não vai melhorando de modo significativo, uma vez que, em 2001, se encontravam em estágio "crítico" ou "muito crítico" 52,3\% dos alunos da $4^{\mathrm{a}}$ série, $58,4 \%$ na $8^{\mathrm{a}}$ e $67,4 \%$ no $3^{\circ}$ ano do ensino médio. A matemática não é a única matéria em que os jovens se deparam com dificuldades, mas é a matéria em que são maiores as dificuldades dos alunos.

Para entender as dificuldades escolares dos alunos, foi desenvolvida na França, desde a década de 1980, uma abordagem em termos de relação com o saber, que prioriza a questão do sentido. Consideramos esta exigência ainda mais valiosa quando se trata de ensinar e aprender uma matéria que carrega tantos preconceitos e estereótipos como a matemática.

Com base nessa abordagem, realizamos no período de 2004 a 2006, em São Cristóvão, na área metropolitana de Aracaju (SE), uma pesquisa de campo sobre "Relação com o saber e matemática". Essa pesquisa visa melhor entender qual o sentido da matemática e do seu ensino para os alunos de $1^{\mathrm{a}}$ à $5^{\mathrm{a}}$ série do ensino fundamental, isto é, de outra forma, retornar "às coisas mesmas", como dizia o filósofo Husserl (Dartigues, 2002). Também, ela abre possibilidade para reflexão acerca das práticas educativas e da importância da didática na formação dos professores. Contudo, cabe ressaltar que a pesquisa e este artigo pretendem contribuir para o desenvolvimento de uma linha brasileira de investigação sobre a questão da relação com o saber, mais do que produzir novos resultados em didática da matemática, embora a sua ambição encontre reflexões de pesquisadores da área de educação matemática, em particular Nilson José Machado e Rômulo Lins. 


\section{A questão da relação com o saber: a problemática da pesquisa}

A expressão "relação com o saber" foi utilizada pela primeira vez, ao que parece, por Lacan, em 1966 (Beillerot et al., 1989). Encontram-se no livro La reproduction, de Bourdieu e Passeron, de 1970, expressões próximas: "relação com a cultura", "relação com a linguagem e o saber". Entretanto, é Bernard Charlot que, na década de 1980, introduz a expressão e o conceito na área da educação e, na década de 1990, elabora "elementos para uma teoria" da relação com o saber (Charlot, 2000 - tradução de um livro publicado em francês em 1997). ${ }^{1}$ A sua questão fundamental é a do fracasso escolar, a mesma nossa aqui.

Nos anos de 1960 e 1970 foi desenvolvida na França (Bourdieu \& Passeron, 1970; Baudelot \& Establet, 1971) e nos Estados Unidos (Bowles \& Gintis, 1976) uma teoria sociológica chamada de teoria da reprodução. Respaldada em numerosas estatísticas, evidencia que a escola, longe de ser um instrumento de democratização da sociedade, como se pensava, contribui para a reprodução das desigualdades sociais: é grande a probabilidade que os filhos das classes dominantes tenham melhor sucesso escolar do que os filhos das classes "desfavorecidas" e, por isso, consigam um melhor lugar no mercado do trabalho e na sociedade. As hierarquias sociais que marcam a geração dos pais são reproduzidas na geração dos filhos.

Sem contestar essa probabilidade, a respeito da qual não resta dúvida alguma, Charlot levanta algumas questões sobre a própria teoria (Charlot, 2000, 2005). Na escola ensinam professores que, na maioria das vezes, sustentam a idéia de democratização social pela escola: como é que estes produzem uma "reprodução" que beneficia o capitalismo, os dominantes, os potentes?

${ }^{1}$ Charlot se interessou pela matemática, embora esta não seja foco das suas pesquisas (Bkouche; Charlot; Rouche, 1991).
Bourdieu empreendeu responder a essa objeção. Ele fala em termos de habitus (conjunto de disposições psíquicas adquiridas cedo na vida e que condizem com as condições sociais de vida do indivíduo) e de capital cultural (transmitido aos filhos pela família). Nas suas famílias, os filhos das classes dominantes constroem habitus e herdam formas de capitais culturais que condizem com os que o êxito escolar requer. Sendo assim, eles têm mais êxito na escola mais do que os filhos das classes desfavorecidas.

Porém, objeta Charlot, ora a noção de habitus é mecânica demais, ora resta explicar como e por que o habitus pode mudar ao longo da vida. E, se pode mudar, por que descartar a idéia de que a escola possa mexer com os habitus e, sendo assim, contribuir para mudar os destinos sociais? Quanto à idéia de capital cultural, não passa de uma metáfora, já que a transmissão cultural e o êxito escolar não são processos automáticos em que os filhos possam ficar passivos; são efeitos de uma atividade dos pais e dos filhos. Para ser bem-sucedido na escola, não é suficiente ser "filho de...", é preciso também estudar, ter uma atividade intelectual. Charlot julga que a questão da atividade intelectual, em particular a questão do acesso intelectual ao saber, foi ignorada pela sociologia da reprodução, a qual focou apenas o acesso social ao saber. Se existe uma desigualdade social perante a escola é porque há uma desigualdade social diante do saber. Portanto, Charlot levanta a questão da relação social com o saber.

Essa questão leva-o a ampliar a sua perspectiva de análise para contemplar, ao mesmo tempo, as dimensões social e subjetiva do problema. Com efeito, por mais social que seja um indivíduo (se não fosse social não seria humano), ele é também um sujeito original, com a sua vida psíquica e a sua história pessoal. É preciso pensar ao mesmo tempo o ser humano, o ser social e o sujeito singular, ressalta Charlot. Em particular, aprender é apropriar-se, por uma atividade intelectual pessoal, de um patrimônio comum aos homens.

Portanto, a questão da atividade intelectual passa a ser fundamental na teorização da questão do sucesso 
e fracasso escolar. Mais particularmente, Charlot levanta a questão das fontes da mobilização intelectual. $\mathrm{O}$ que faz com que o ser humano, coletiva e individualmente, se mobilize intelectualmente, entre em um processo de atividade intelectual, tente aprender? Daí as três questões que Charlot (2005, p. 59) apresenta como básicas:

1) para um aluno, especialmente de meios populares, qual o sentido de ir à escola?

2) para ele, qual o sentido de estudar ou de não estudar na escola?

3) qual o sentido de aprender, de compreender, quer na escola quer fora dela?

Esse questionamento, referido à matemática, embasa a nossa pesquisa. Para um aluno, qual o sentido de estudar a matemática, na escola ou fora dela? De modo mais geral, qual o sentido dessa matéria que se chama matemática, da atividade matemática, dos objetos matemáticos? O objetivo prático e social de Charlot é nosso também: contribuir para uma democratização da escola graças a uma melhoria do processo de ensino-aprendizagem na escola pública brasileira. Hoje em dia, em uma escola pública situada na área metropolitana de Aracaju, por que os alunos têm vontade, ou não têm, de estudar matemática?

Esse campo da relação com o saber, aberto por Charlot e sua equipe na área da educação, foi explorado por outros pesquisadores também. Entre eles, cabe destacar Jacky Beillerot e sua equipe, e Yves Chevallard e os didáticos da matemática.

Embora haja um confronto teórico entre a abordagem de Charlot, mais social, e a de Beillerot, mas "psicofamiliar" e psicanalítica, esta pode ser considerada complementar àquela. Com efeito, ela foca $o$ desejo e os processos pelos quais ele muda de forma e objetos, incluídos os produtos e processos inconscientes. Ora, Charlot remete explicitamente a noção de mobilização à questão do desejo, e aceita a hipótese do inconsciente, embora não tivesse pesquisado diretamente esses temas. Ao ver de Beillerot:
Todo estudo que tomar a relação com o saber como noção central não poderá libertar-se da base psicanalítica; não que isso impeça outras abordagens, mas é a partir da teorização da relação de objeto, do desejo e do desejo de saber, depois da inscrição social destes em relações (que vinculam o psicológico ao social) que será possível assumir o risco de trabalhar com essa noção e de desenvolvê-la; um desenvolvimento que não deverá esquecer algo essencial, sob pena de fazê-la perder seu sentido: só há sentido do desejo. (Beillerot, Blanchard-Laville \& Mosconi, 1996, p. 73$)^{2}$

Só há sentido do desejo: como aponta o próprio Charlot (2000, 2005), é nessa asserção que podem ser articuladas a sua abordagem e a de Beillerot. Só há sentido do desejo: para nós também, é isso, antes de tudo, que importa na nossa própria pesquisa. Ao aprofundar a questão sobre o sentido da matemática e do ensino da matemática, encontra-se a questão do desejo. De que se gosta quando se gosta da matemática? De acordo com a psicanálise, o desejo não tem objetos determinados, ele visa somente ao "gozo" e, no decorrer da vida psíquica, chega a ser ligado a tal ou qual "objeto" (noção que, na psicanálise, inclui as pessoas). Como a procura do gozo pode ser satisfeita pelo encontro dos números, do m.m.c. ou de um teorema? É também essa a questão da relação com o saber matemático.

Vale a pena, ainda, evocar as teses de BlanchardLaville e de Hatchuel, que são professoras de matemática e seguidoras de Beillerot. Claudine BlanchardLaville (1997) defende a idéia de que cada docente, pela sua fala e, de modo mais geral, pela maneira como organiza a sua aula, constrói e impõe aos alunos um determinado roteiro-cenário, específico dele. Não se trata apenas de uma produção didática, mas também, e acima de tudo, de um "espaço psíquico". "Mostrei que a relação do docente com o saber se atualiza de maneira singular por cada docente no espaço psíquico da classe, caminho para a transposição, e que ele

\footnotetext{
${ }^{2}$ Ver também Mosconi, Beillerot e Blanchard-Laville, 2000.
} 
molda este espaço para a turma de alunos" (BlanchardLaville, 2003, p. 152). ${ }^{3}$ Por analogia com o conceito de transposição didática, e usando a noção psicanalítica de "transferência", Blanchard-Laville dá a esse processo o nome de "transferência didática". Não pretendemos usar essas idéias na nossa pesquisa, na medida em que a relação entre docentes e alunos não constitui um objeto dela, mas essas reflexões valem por lembrar-nos da importância da relação com o docente na elaboração da relação com a matemática.

Encontra-se ainda uma idéia muito interessante no recente livro de Françoise Hatchuel (2005). Novamente, a questão do desejo é o ponto de partida: trata-se de pesquisar "a questão do desejo de saber, e, portanto, do que o saber representa do ponto de vista fantasmático para o sujeito" (p. 11). Hatchuel considera que "a questão da relação com o saber é antes de tudo a do vínculo e da autonomia do sujeito" (p. 137). Ela ressalta a ambivalência do desejo de saber: "Portanto a pulsão de saber enraíza-se em um desejo de autonomia, desejo de substituir o adulto-objeto, de se livrar dele, mas com o risco de ele entrar no jogo e aceitar, enquanto não se tem certeza absoluta de poder assumi-lo" (p. 49). Em outras palavras, aprender é também o caminho para "passar a ser alguém" (devenir quelqu'un), como dizem os jovens entrevistados por Charlot, e também os alunos que responderam a nossas perguntas, como veremos. Ser alguém, com todo o orgulho de quem é livre e toda a angústia de quem já não aproveita da proteção absoluta de papai e mamãe. Aprender é arriscar, exporse ao risco de fracassar e, ainda, ao risco de ser bemsucedido, adulto, sozinho.

Por fim, o conceito de relação com o saber foi adotado também pelos didáticos franceses e canadenses, em particular na área da didática da matemática e das ciências. Nessa área, foi Yves Chevallard que desempenhou o papel fundamental. Chevallard é conhecido por ter introduzido e desenvolvido na área da di-

${ }^{3}$ Quando um livro francês foi traduzido para o português, citamos a tradução publicada. Quando existe apenas o texto francês, responsabilizamo-nos pela tradução. dática o conceito de "transposição didática" (formulado pela primeira vez pelo sociólogo Michel Verret, na sua tese de doutorado). Chevallard estabeleceu que não se ensina o próprio saber científico, mas sim uma versão transposta dele, um saber adaptado para ser ensinado, um saber "escolar". Essa idéia, que passou a ser um conceito "clássico" da didática, constitui, na verdade, uma primeira versão das idéias defendidas por Chevallard. A segunda versão junta o conceito de relação com o saber ao conceito de transposição.

Nessa teorização, ${ }^{4}$ Chevallard leva em consideração o aluno, ao passo que pouco fala dele no conceito de transposição didática. Articula os conceitos de relação pessoal e de relação institucional com o saber. Por instituição deve-se entender as instituições públicas, como a escola, mas também, de acordo com o sentido mais geral dessa noção na antropologia, a família, a religião, a linguagem, uma aula de matemática etc. As instituições mantêm relações específicas com os objetos de saber ou, de modo mais geral, com o saber. Quando uma pessoa pertence a uma instituição, ou participa no seu funcionamento, se quiser apropriar-se do saber ligado a ela deve entrar na relação institucional característica dessa instituição. Portanto, a relação pessoal com o saber constrói-se à articulação das relações com o saber específicas das várias instituições a que pertence um indivíduo (Chevallard, 2003). De Chevallard, na nossa pesquisa, retivemos a idéia de que a relação com o saber que pesquisamos não é a relação de um indivíduo abstrato ou de "um menino"; é, sim, a relação de um menino matriculado em uma instituição chamada de escola, onde ocupa um lugar particular e desempenha um papel específico, o de aluno. ${ }^{5}$

${ }^{4}$ Não se encontram facilmente os textos de Chevallard sobre a relação com o saber. O texto mais fácil de ser encontrado é o capítulo que ele escreveu no livro Rapport au savoir et didactiques (organizado por Maury \& Caillot, 2003b).

${ }^{5}$ Mas às vezes a estética contesta as regras da sociologia: para não repetir sempre a palavra "aluno", tivemos de vez em quando de substituí-la por "menino". Queremos deixar claro que 
As várias abordagens que acabamos de apresentar dizem respeito à questão da relação com $o$ saber, no singular. Entretanto, por mais interessantes que sejam essas teorizações, não são suficientes para resolver a questão da relação com a matemática. A matemática é uma disciplina específica, um conjunto particular de saberes, e o que nos interessa é entender qual é a relação específica dos alunos com essa disciplina. Ora, encontramos muito poucos textos sobre a relação com a matemática ou, por sinal, com qualquer outra disciplina que não a matemática. Até agora, os pesquisadores trataram do saber no singular, isto é, do fato de adquirir um conhecimento pela aprendizagem e do que foi assim adquirido, sem particularizar os conteúdos dos saberes. Contudo, literatura, história, biologia e matemática, por exemplo, são disciplinas bem diferentes, e é difícil acreditar que a relação com o saber seja igual em todos esses casos.

Já foram pesquisados alguns conceitos na perspectiva da relação com o saber (ver Chabchoub, 2000, 2001; Maury \& Caillot, 2003a). Na Tunísia, Yassine Jelman pesquisou as relações com o conceito de raio entre alunos que se deparam com a contradição entre a explicação científica e a fala religiosa. Na França, Jean-Louis Chartrain defendeu uma tese de doutorado sobre a relação dos alunos com o conceito de vulcão. Todavia, entre a relação com "o" saber, no singular, e a relação com tal ou qual conceito, faltam pesquisas intermediárias voltadas para as disciplinas: qual a relação dos alunos com a geografia, a biologia, a matemática?

A questão central da nossa pesquisa é: qual é a relação dos alunos com a matemática, enquanto disciplina ensinada na instituição escolar? A pesquisa trata de alunos da escola pública, em um bairro popular. Trata, ainda, de alunos das primeiras séries, na medida em que tentamos compreender como se constrói a relação de alunos com a matemática. No entan-

este "menino" (que, por sinal, pode ser uma menina), na maioria das vezes é um menino-aluno. to, a pesquisa foi prolongada até a $5^{\mathrm{a}}$ série, pois é também interessante comparar os resultados das séries iniciais e da $5^{\mathrm{a}}$ série, em que os alunos seguem o ensino de um professor "de matemática", específico.

Pode-se expressar a questão da relação com o saber de várias formas:

- Para os alunos, especialmente em um bairro popular, qual o sentido de estudar a matemática na escola e de usá-la fora da escola?

- Qual a fonte da mobilização intelectual, qual o desejo (quais os desejos) que fomenta(m), sustenta(m) o estudo da matemática? Como se pode gostar (gozar) da matemática quando se é uma criança?

- Qual o espaço psíquico do aluno que estuda a matemática? Qual a imagem de si mesmo, em particular na dialética autonomia - proteção?

- Qual "relação institucional com o saber" pode ser percebida pela "relação pessoal" dos alunos com a matemática? O que significa "ser um aluno estudando a matemática”?

\section{A relação com o saber de alunos do ensino fundamental: metodologia e resultados de pesquisa}

A pesquisa "Relação com o saber e matemática" foi realizada em São Cristóvão, na área metropolitana de Aracaju (SE), entre julho de 2004 e março de 2006 , junto a alunos da $1^{\mathrm{a}}$ à $5^{\mathrm{a}}$ série. Foram pesquisados 362 alunos, assim distribuídos:

- 178 meninos e 184 meninas;

- 61 alunos de $1^{\mathrm{a}}$ série, 47 de 2a, 70 de 3a, 67 de $4^{\mathrm{a}}$ e 117 de $5^{\mathrm{a}}$ série.

A idade desses alunos varia de 5 a 17 anos; todavia, a maioria deles tem entre 8 e 13 anos.

As atividades dos pais e das mães podem ser consideradas representativas das classes populares ou classe média baixa, que escolarizam os seus filhos na escola pública, em particular em um bairro como Rosa 
Elze, em São Cristóvão, onde foi realizada a pesquisa. Os pais trabalham nos setores definidos pelo Instituto Brasileiro de Geografia e Estatística (IBGE) como construção, manutenção de casa, comércio, artesanato, serviços prestados às empresas, ou são pequenos funcionários públicos; as mães são donas de casa, empregadas domésticas ou trabalhadoras do comércio. Portanto, podemos considerar a nossa população de pesquisa como a população habitual de uma escola pública situada em um bairro urbano popular.

Os dados foram recolhidos por meio de um questionário com 14 perguntas abertas. Tendo em vista que pesquisamos a questão do sentido da matemática para o aluno, com o propósito de melhor entender as suas dificuldades, definimos três grupos de perguntas sobre: 1) a importância e utilidade da matemática e da sua aprendizagem; 2) o êxito e fracasso em matemática; 3 ) a relação pessoal do aluno com a matemática.

Sabemos que o próprio fato de perguntar com insistência sobre um tema pode induzir um viés metodológico. Para evitar esse viés, distribuímos em dois lugares diferentes as perguntas atinentes ao primeiro tema, o que permite também que as perguntas a respeito da relação pessoal do aluno com a matemática não se sigam imediatamente às sobre o fracasso em matemática. Ainda, introduzimos perguntas para os alunos compararem português e matemática, já que, segundo os dados do Sistema de Avaliação da Educação Básica (SAEB), existem dificuldades escolares em ambas matérias. Sendo assim, e depois de ter realizado uma pré-enquete para testar as perguntas, foram retidas as seguintes.

1) Acerca da importância e utilidade da matemática e da sua aprendizagem:

Q1. Por que se aprende a matemática? É importante, é útil?

Q2. Você já encontrou a matemática fora da escola? Por favor, explique quando e onde.

Q8. Será que a matemática é importante para o futuro do Brasil?
Q9. Você acha que existe profissão em que é mais importante ser bom em matemática do que outras? Quais? Por quê?

2) Acerca do êxito e fracasso em matemática:

Q3. Todo mundo pode ser bom em matemática? Por quê?

Q4. É possível ser bom em matemática e em português? Por quê?

Q5. Para ser bom em matemática:

a) $\mathrm{Na}$ sua opinião, o fato de ser jovem ou adulto facilita a aprendizagem da matemática? Por quê?

b) Na sua opinião, o fato de ser homem ou mulher facilita a aprendizagem da matemática? Por quê?

c) Na sua opinião, o fato de ser rico ou pobre facilita a aprendizagem da matemática? Por quê?

Q6. Será que é grave se fracassar em matemática na escola? Por quê?

Q7. Qual é mais grave: fracassar em matemática ou em português? Por quê?

3) Acerca da relação pessoal do aluno com a matemática:

Q10. Você acha que é bom em matemática? Por quê?

Q11. Uma pessoa pode ser inteligente e, apesar disso, fracassar em matemática? Por quê? Q12. Você gosta de aprender a matemática? Por quê?

Q13. Seus pais são bons em matemática? Como sabe disso?

Q14. Você lembra de uma coisa que gostou muito de aprender em matemática? Qual?

O questionário foi aplicado em todas as turmas matutinas de $1^{\mathrm{a}}, 2^{\mathrm{a}}, 3^{\mathrm{a}}$ e $4^{\mathrm{a}}$ séries, como previsto no projeto de pesquisa. A pedido do pessoal da escola, foi também aplicado em todas as $5^{\text {a }}$ séries vespertinas, tendo sido esse pedido acatado sem nenhuma hesitação nossa, pelas razões já mencionadas.

A análise associou métodos quantitativos e qualitativos, como é possível quando se usam perguntas 
abertas: com base nas respostas, foram construídas categorias e calculadas percentagens, mas também foi analisado o conteúdo de forma mais detalhada, a fim de levar em consideração nuanças. Por fim, além da abordagem geral, foi introduzido um duplo ponto de vista comparativo: entre os dois sexos e entre os níveis de escolaridade.

Não se pode tratar aqui detalhadamente de uma pesquisa que nos levou a redigir um relatório com quase 200 páginas. Portanto, apresentamos a seguir apenas seus principais resultados, que podem ser sintetizados em torno de dois eixos:

a) todo mundo pode aprender a matemática, porém é uma matéria particularmente difícil e importante;

b) qual desejo sustenta a aprendizagem da matemática e qual é o objeto desse desejo?

\section{Todo mundo pode aprender a matemática, mas é uma matéria difícil e importante}

A maioria dos alunos considera que todo mundo pode aprender a matemática, com o argumento: "é só estudar". Esse argumento é o mais freqüente entre os que dizem que cada um pode ser bom em matemática. Reciprocamente, dizem que se pode fracassar em matemática, apesar de ser inteligente, quando não se estuda o suficiente. "É só estudar" constitui também o argumento mais evocado quando os alunos explicam que o fato de ser jovem ou adulto, homem ou mulher, rico ou pobre não incide no êxito ou fracasso em matemática. Ainda, é porque "é só estudar" que a maioria responde que é possível ser bom ao mesmo tempo em matemática e em português. Quando se trata do seu caso pessoal, os alunos hesitam mais, porém ainda a maioria considera que a matemática é acessível: $47 \%$ se declaram bons; $12 \%$, "mais ou menos"; e $34 \%$, ruins. Sabem que são bons ou ruins pela nota que tiram, mas explicam o porquê pelo fato de estudarem muito ou pouco.

Portanto, os alunos não raciocinam nem a partir da lógica do dom, nem da reprodução familiar. Aliás, a maioria (70\%) considera que seus pais são bons em matemática.

Entretanto, há uma forte minoria que não funciona do modo que acabamos de relatar. Esses alunos negam que todo mundo possa ser bom em matemática (44\%). Consideram que não se fracassa em matemática quando se é inteligente (22\%). Pensam que não é possível ser bom em matemática e português $(25 \%)$ e, na maioria das vezes, valorizam o português em detrimento da matemática ( $81 \%$ ). Julgam-se ruins em matemática (34\%). Portanto, podemos concluir que um quarto ou um terço dos alunos mantêm certa ressalva ou resistência para com a matemática.

Ademais, apesar de considerarem que todos podem aprender matemática, a maioria dos alunos temna por uma matéria difícil. É porque ela não é fácil que se pode entender que uma pessoa fracasse em matemática apesar de ser inteligente e, também, que é mais difícil ser bom em matemática do que em português. Ainda, é mais grave fracassar em matemática, uma vez que é mais trabalhoso recuperar-se em uma matéria difícil.

Além de ser difícil, a matemática é "importante". Quando perguntados sobre as profissões em que é útil ser bom em matemática, alguns alunos são convencidos da importância desta a ponto de citar profissões sem relação particular com a matemática, mas importantes "por si”, como médico, advogado, jornalista ou modelo. É como se alguém que pratica uma profissão importante tivesse de conhecer coisas importantes e difíceis.

Concluímos que a maioria dos alunos da $1^{\mathrm{a}}$ à $5^{\mathrm{a}}$ série não raciocina a sua relação com a matemática em uma lógica do dom ou da carência sociocultural, mas sim em uma lógica do estudo, da atividade intelectual, da mobilização: quem estuda será bem-sucedido, quem não estuda o suficiente fracassará.

Do ponto de vista pedagógico e didático, esse resultado leva a considerações otimistas: a escola pode ensinar matemática a quem considera que é capaz, "é só estudar". A dificuldade é saber como fazer para que os alunos estudem, se mobilizem intelectualmente. Além disso, é preciso não esquecer a forte minoria 
de alunos pensando que nem todos podem ter êxito em matemática, e que eles mesmos, em particular, não têm uma cabeça matemática. Com essa minoria, é também a relação profunda com a matemática que terá de ser mudada.

\section{Por que aprender a matemática? Qual desejo? Qual objeto do desejo? Qual matemática?}

Como já destacado, a questão da mobilização intelectual, conceituada por Charlot na teoria da relação com o saber, leva a colocar a questão do desejo, ressaltada nas pesquisas de Beillerot e sua equipe. Para aprender a matemática, é preciso ter um desejo. Qual desejo, desejo de que, de qual matemática? Esse é o eixo da nossa segunda síntese da fala dos jovens.

Primeira resposta, com base no que disseram os próprios alunos: aprende-se matemática porque é ensinada. $48 \%$ dos alunos da $1^{\mathrm{a}}$ à $4^{\mathrm{a}}$ série negaram que haja matemática fora da escola ou evocaram os deveres de casa; $30 \%$ dos alunos da $5^{\text {a }}$ série responderam o mesmo. Na mesma lógica, os jovens citam os professores de matemática entre as profissões em que é importante ser forte em matemática. Da mesma forma, muitas vezes os alunos insistem na nota e no fato de passarem de ano ou serem reprovados. Essa é a resposta mais freqüente (27\%) quando explicam por que é grave fracassar em matemática.

Para os alunos que mantêm essa relação com o saber, a matemática não passa de um objeto escolar. A escola operou uma transposição didática do saber científico para o saber escolar, mas, para os alunos, não há transposição: só existe um objeto escolar. Aos olhos desses alunos, na escola estuda-se o que a escola ensina, sem mais justificativas. Em uma situação dessas, o único desejo que pode sustentar a aprendizagem da matemática é o de ficar em conformidade com as exigências da instituição escolar. $\mathrm{O}$ que não seria possível, claro, se não existissem outros desejos embasando este - do que falaremos adiante.

Segunda resposta à questão sobre o desejo: aprende-se a matemática porque é imprescindível na vida cotidiana, para verificar o seu troco, comprar coisas, contar dinheiro etc. Dessa forma, as profissões em que, na opinião dos alunos, é preciso ser bom em matemática, são aquelas em que se mexe com dinheiro: vendedor, balconista, caixa, bancário, contador etc. São também as profissões em que há de saber medir, quer se trate do quarto (pedreiro), da roupa (costureira), até do leite (babá).

Nas respostas dos alunos percebe-se uma ligação forte entre matemática e dinheiro. Provavelmente seja por isso que ser rico ou pobre é o critério que mais induz resposta afirmativa quando se pergunta aos alunos se facilita ser jovem ou adulto, homem ou mulher, rico ou pobre para aprender matemática. É como se, sem querer nem saber, os alunos equiparassem os dois produtos mais abstratos já concebidos pelos homens: a matemática, que pode simbolizar quase todas as formas do saber, e o dinheiro, que representa o valor de tudo que se vende e compra.

Esse vínculo forte entre matemática e vida cotidiana, estabelecido pelos alunos, gera uma conseqüência pedagógica preocupante: depois de assim ter restringido a matemática a seus saberes rudimentares, poder-se-ia sustentar a idéia de que se pode prescindir de mais matemática.

Terceira resposta à questão sobre o desejo para a matemática: esta é necessária para ter um bom emprego mais tarde. Notem que não é a própria matemática que é objeto do desejo, é o que ela pode trazer, ou seja, o bom emprego. $\mathrm{O}$ argumento pode apresentar-se de forma individual ou coletiva: é grave fracassar em matemática porque quem fracassa não consegue um bom emprego; a matemática é importante para o Brasil tornar-se mais rico. Na verdade, essa relação com o saber completa a primeira anteriormente exposta: o desejo de conformidade com as exigências da instituição escolar é, no fundo, desejo de passar de ano, o qual é, de fato, desejo de sucesso social e econômico.

Levando em consideração os três tipos de resposta, pode-se levantar a questão de saber o que, na verdade, se ensina com o nome de matemática. A professora acha que ensina atividades e objetos específicos de um campo de saber chamado de matemática pelo menos é de esperar que esta seja a concepção da 
professora. Mas não é isso que aprende a maioria dos alunos: eles estudam práticas sociais com números (contar dinheiro, medir coisas etc.) e objetos escolares impostos pela escola para o aluno passar de ano e esperar ter um bom emprego mais tarde. Até que alguns alunos consideram que há matemática onde há números, inclusive para identificar uma casa na rua, um ônibus, ou o partido político em que se quer votar. Levando essa idéia a cabo, pode-se dizer que muitos alunos mantêm uma relação com a matemática que não é uma relação de tipo matemático; na verdade, trata-se de uma relação prática, social e, algumas vezes, imaginária. ${ }^{6}$

Essa relação com o saber é também uma relação com o mundo, com os outros e consigo mesmo, para usar a fórmula divulgada por Charlot: mundo da concorrência, do dinheiro, do desemprego, da necessidade de esforçar-se para aprender coisas difíceis, mas úteis no presente e importantes para o futuro. Esse tipo de relação com o saber possibilita sobreviver no universo escolar, em "passando de ano". Mas é muito diferente da relação oficial da escola com o saber, como diria Chevallard, a qual destaca a formação da pessoa, a cultura, o prazer e até a sorte de aprender.

Entretanto, a nossa pesquisa entreviu essa relação institucional com a matemática. Em primeiro lugar, apesar de tudo, há uma minoria de alunos que respondem evocando a própria atividade matemática ou objetos matemáticos, até, embora seja raro, o prazer de estudar a matemática. Mais interessante ainda, a situação paradoxal que enxergamos quando analisamos as respostas à questão "você gosta de aprender matemática?”. Os alunos dizem que gostam, sem dúvida nenhuma (86\%). Mais ainda: a metade das explicações diz respeito ao gosto pela pró-

${ }^{6}$ Por exemplo, quando os alunos citam o advogado e a modelo como profissões em que é preciso ser bom em matemática. Trata-se de uma relação imaginária, ao mesmo tempo com essas profissões e com a matemática, a não ser que se considere que eles precisam da matemática para contar a fortuna que (provavelmente...) ganham. pria atividade matemática ou por objetos matemáticos. Também, $89 \%$ dos alunos lembram-se de uma coisa que gostaram muito de aprender em matemática - na maioria das vezes (77\%), fazer contas. Entretanto, gostar é um argumento que se encontra muito pouco nas respostas dos alunos às outras perguntas. Como se pode entender essa situação paradoxal: alunos que dizem gostar da matemática, mas quase nunca usam o argumento do gosto quando indagados sobre a disciplina?

A pesquisa mostra que os alunos gostam da matemática quando estão na $1^{\mathrm{a}}$ série $(98 \%)$, mas que esse gosto vai diminuindo ( $72 \%$ na $5^{\mathrm{a}}$ série). Percebemos também que eles, e ainda mais elas, constroem aos poucos uma imagem negativa de si mesmos perante o ensino da matemática. $\mathrm{Na} 1^{\mathrm{a}}$ série, $50 \%$ dos meninos e $81 \%$ das meninas respondem que são bons em matemática, enquanto na $5^{\mathrm{a}}$ série os percentuais são apenas $44 \%$ dos meninos e $18 \%$ das meninas. Essa queda brutal da percentagem tocante às meninas não pode ser atribuída ao preconceito, uma vez que os alunos não pensam que o fato de ser mulher dificulta a aprendizagem da matemática (ao contrário, tendem a valorizar as mulheres). Tampouco se pode falar em uma resistência das meninas em esforçar-se, uma vez que vários índices confirmaram um resultado já estabelecido pela sociologia da educação: as meninas esforçam-se mais do que os meninos para serem "boas alunas". Resta que, na nossa pesquisa, as meninas perdem a confiança em suas capacidades matemáticas ao longo de sua escolaridade. Por quê? Para responder a essa questão, seria preciso uma pesquisa aprofundada - depois de ter verificado em outros lugares que não se trata de uma diferença local (o que, do ponto de vista estatístico, é pouco provável).

A pesquisa evidencia também que a idéia de que se vai à escola para ter um bom emprego mais tarde passa a ser mais freqüente da $1^{\mathrm{a}}$ à $5^{\mathrm{a}}$ série.

Por fim, mostra ainda que a maioria dos jovens não confunde inteligência e êxito escolar em matemática - o que protege a imagem de si mesmos dos que fracassam. 
Em síntese, alunos que gostavam, nas $1^{\mathrm{a}}$ e $2^{\mathrm{a}}$ séries, da matemática, e que alegavam muitas vezes o estudo como argumento nas suas respostas, perdem aos poucos esse gosto e, ainda, a confiança em si mesmos, e argumentam cada vez mais em termos de "passar de ano" e "ter um bom emprego mais tarde". Gostavam, mas encontraram a matemática como matéria "difícil", fracassaram e perderam o gosto. Sendo assim, já nem se trata de gostar ou não gostar, trata-se sim de tirar notas boas e passar de ano. A lógica do saber e do prazer é substituída pela lógica da sobrevivência escolar e da concorrência social para os empregos.

Afinal de contas, qual é a relação dos alunos com a matemática?

Uma pequena minoria mantém com ela uma relação de prazer: prazer da própria atividade, prazer de ter êxito e sentir-se inteligente, prazer de passar a "ser alguém na vida".

Uma minoria mais ampla (um quarto ou um terço dos alunos) sofre um fracasso e, além do fracasso objetivo, a dor psíquica de sentir-se fraco, até pouco inteligente.

Entre essas duas minorias, a maioria dos alunos gostaria da atividade matemática, em particular de fazer contas, se esta não fosse tão difícil. Eles esforçam-se, por saberem que a matemática é "importante": na vida cotidiana, para passar de ano, para ter um bom emprego mais tarde. Esforçam-se, mas perderam o prazer.

Nessa situação, as práticas pedagógica e didática das professoras e, de modo mais geral, da instituição escolar, cumprem uma função essencial.

\section{Escolhas pedagógicas. A questão do "Eu epistêmico"}

Já foram desenvolvidas várias reflexões sobre a didática e, em especial, a didática da matemática, quer em países de língua francesa, quer no Brasil (Libâneo, 1990, 1998; Johsua \& Dupin, 1993; Pimenta, 1999; Tardif \& Lessard, 1999; Tosi, 2001; Parra \& Saiz, 2001; Rosa \& Souza, 2002; Veiga, 2003 etc.). De nossa parte, para interpretar os resultados da pesquisa e con- tribuir para a didática da matemática e das ciências, defendemos a idéia de dialética continuidade/ruptura entre o saber cotidiano e o saber científico.

Pode-se argumentar essa idéia respaldando-se em Bachelard: entre "o senso comum" (“a opinião"), construído na experiência cotidiana, e o saber científico não há continuidade, há sim uma ruptura, chamada por Bachelard de "ruptura epistemológica" ou "corte epistemológico" (Bachelard, 1996, 1991). Todavia, não se deve esquecer o "outro" Bachelard, que desenvolveu uma "psicanálise" do espírito científico. Com efeito, esse autor explica também que sempre se começa pelo erro, pois sempre se começa pela vida. Vivemos, construímos as nossas primeiras e básicas representações do mundo e, mais tarde, entramos em um processo de "retificação" das idéias anteriores, o qual forma aos poucos o espírito científico. Conforme Bachelard, o papel da matemática é fundamental para romper com a opinião e pensar o mundo com uma linguagem científica (Fabre, 1995; Silva, 2002, 2004).

Retemos de Bachelard a idéia de que o Eu epistêmico se constrói por diferenciação progressiva do Eu empírico. A professora está errada quando ignora o Eu empírico. Está errada também quando aceita o domínio deste e renuncia a construir o Eu epistémico.

Pode-se igualmente abordar essa questão com base nas obras de Vygotsky $(1987,1996)$. Para Vygotsky, os "conceitos científicos" têm uma origem e uma natureza diferentes dos "conceitos cotidianos" (ou "espontâneos"). Aqueles são sistemáticos, voluntários e conscientes, à diferença destes. Todavia, os dois tipos de conceitos são interdependentes. É somente quando o conceito científico encontra "o tecido já elaborado dos conceitos cotidianos" que ele toma sentido - e ao mesmo tempo, os conceitos espontâneos acedem a um estágio superior de desenvolvimento. Os conceitos científicos "germinam para baixo" e os conceitos quotidianos "germinam para cima". Quem ignora os conceitos cotidianos introduz na escola palavras sem sentido. Quem ignora a natureza do conceito científico renuncia a desenvolver o pensamento dos seus alunos. 
Concluindo, não se trata apenas de ensinar saberes úteis, trata-se ainda e acima de tudo de transmitir ao professor as indagações levantadas e estudadas pela didática, na perspectiva filosófica de Husserl: "é o retorno incessante à intuição originária", "fonte de direito para o conhecimento", o que Husserl chama de princípio dos princípios (Dartigues, 2002). Por isso, acreditamos que essa pesquisa de campo possa contribuir para a reflexão da didática sobre as práticas educativas. Como escreve Libâneo: "O processo de ensino é uma atividade conjunta de professores e alunos, organizado sob a direção do professor, com finalidade de prover as condições e meios pelos quais os alunos assimilam ativamente conhecimentos, habilidades, atitudes e convicções. Este é o objeto de estudo da Didática" (Libâneo, 1990, p. 29). ${ }^{7}$ É a partir dessas idéias que esperamos os efeitos do saber novo. Sendo ele articulado com o saber já disponível, e misturado com o saber empírico dos professores construído ao longo da sua atuação profisssional, com certeza experimentaremos o sabor de uma nova fonte de saber, uma nova sociedade calcada na sabedoria da sociedade antiga.

\section{Referências bibliográficas}

BACHELARD, Gaston. Le nouvel esprit scientifique. Paris: PUF, 1991. A formação do espírito científico. Rio de Janeiro: Contraponto, 1996.

BAUDELOT, Christian; ESTABLET, Roger. L'école capitaliste en France. Paris: Maspero, 1971.

BEILLEROT, Jacky; BOUILLET, Alain; BLANCHARDLAVILLE, Claudine; MOSCONI, Nicole. Savoir et rapport au savoir. Paris: Éditions Universitaires, 1989.

BEILLEROT, Jacky; BLANCHARD-LAVILLE, Claudine; MOSCONI, Nicole (Orgs.). Pour une clinique du rapport au savoir. Paris: L'Harmattan, 1996.

BKOUCHE, Rudolph; CHARLOT, Bernard; ROUCHE, Nicolas. Faire des mathématiques: le plaisir du sens. Paris: Armand Colin, 1991.

\footnotetext{
${ }^{7}$ Ver também Libâneo, 1998.
}

BLANCHARD-LAVILLE, Claudine (Org.). Variations sur une leçon de mathématiques. Paris: L'Harmattan, 1997.

Rapport au savoir et approche clinique des pratiques enseignantes. In: MAURY, Sylvette; CAILLOT, Michel (Orgs.). Rapport au savoir et didactiques. Paris: Fabert, 2003. p. 145-167. BOURDIEU, Pierre; PASSERON, Jean-Claude. La reproduction. Paris: Minuit, 1970.

BOWLES, Samuel; GINTIS, Herbert. Schooling in capitalist America. New-York: Basic Books, 1976.

BRASIL. Instituto Nacional de Estudos e Pesquisas Educacionais Anísio Teixeira. Resultados do SAEB 2003. Brasília: INEP, 2004.

CHABCHOUB, Ahmed (Org). Rapports aux savoirs et apprentissage des sciences. Tunis: Faculté des Sciences de Sfax, École Nationale des Ingénieurs de Sfax et Association Tunisienne de Recherches Didactiques, 2000.

. Relações com os saberes científicos e cultura de origem. In: CHARLOT, Bernard (Org.). Os jovens e o saber: perspectivas mundiais. Porto Alegre: Artmed, 2001. p. 117-132.

CHARLOT, Bernard. Da relação com o saber: elementos para uma teoria. Porto Alegre: Artmed, 2000.

. Os jovens e o saber: perspectivas mundiais. Porto

Alegre: Artmed, 2001.

Relação com o saber, formação dos professores e

globalização: questões para a educação hoje. Porto Alegre: Artmed, 2005.

CHEVALLARD, Yves. Approche anthropologique du rapport au savoir et didactique des mathématiques. In: MAURY, Sylvette; CAILLOT, Michel (Orgs.) Rapport au savoir et didactiques. Paris: Fabert, 2003. p. 81-104.

DARTIGUES, André. O que é a fenomenologia? São Paulo: Centauro, 2002.

FABRE, Michel. Bachelard éducateur. Paris: PUF, 1995.

HATCHUEL, Françoise. Savoir, apprendre, transmettre: une approche psychanalytique du rapport au savoir. Paris: La Découverte, 2005.

JOHSUA, Samuel; DUPIN, Jean-Jacques. Introduction à la didactique des sciences et des mathématiques. Paris: PUF, 1993. LIBÂNEO, José Carlos. Didática. São Paulo: Cortez, 1990. Pedagogia e pedagogos para quê? São Paulo: Cortez, 1998.

MAURY, Sylvette; CAILLOT, Michel. Quand les didactiques rencontrent le rapport au savoir. In: MAURY, Sylvette; CAILLOT, 
Michel (Orgs.). Rapport au savoir et didactiques. Paris: Fabert, 2003a. p. 13-32.

(Orgs.). Rapport au savoir et didactiques. Paris: Fabert, 2003b.

MOSCONI, Nicole; BEILLEROT, Jacky; BLANCHARD-

LAVILLE, Claudine (Orgs.). Formes et formations du rapport au savoir. Paris: L'Harmattan, 2000.

PARRA, Cecilia; SAIZ, Irma (Orgs.). Didática da matemática, reflexões psicopedagógicas. Porto Alegre: Artmed, 2001.

PIMENTA, Selma Garrido (Org.). Saberes pedagógicos e atividade docente. São Paulo: Cortez, 1999.

ROSA, Dalva E. Gonçalves; SOUZA, Vanilton Camila de (Orgs.). Didática e práticas de ensino: interfaces com diferentes saberes e lugares formativos. Rio de Janeiro: DP\&A, 2002.

SILVA, Veleida Anahi da. Les univers explicatifs des élèves, une question-clef pour la rénovation de l'enseignement des sciences: recherche auprès d'élèves brésiliens du premier et second degrés. 2002. 458f. Tese (Doutorado em Ciências da Educação) - Universidade de Paris 8, Saint-Denis (France), 2002.

Savoirs quotidiens et savoirs scientifiques: l'élève entre deux mondes. Paris: Anthropos, 2004.

TARDIF, Maurice; LESSARD, Claude. Le travail enseignant au quotidien: expérience, interactions humaines et dilemmes professionnels. Laval: Les Presses de l’Université, 1999.

TOSI, Maria Reineldes. Didática geral: um olhar para o futuro. Campinas: Alínea, 2001.
VEIGA, Ilma Passos Alencastro (Org.). Repensando a didática. 20. ed. Campinas: Papirus, 2003.

VYGOTSKY, Lev Sémionovitch. Pensamento e linguagem. São Paulo: Martins Fontes, 1987.

Teoria e método em psicologia. São Paulo: Martins

Fontes, 1996.

VELEIDA ANAHI DA SILVA, doutora em ciências da educação pela Universidade Paris 8 - Saint-Denis (França), é professora do Departamento de Educação e no Programa de Pós-Graduação em Educação na Universidade Federal de Sergipe (UFS), coordenadora do Programa Conexões de Saberes e líder do grupo de pesquisa Educação e Contemporaneidade (EDUCON). Publicações recentes: Savoirs quotidiens et savoirs scientifiques: l'élève entre deux mondes (Paris: Anthropos, 2004); Matemática, relação com o saber e concepções dos alunos de $1^{a}$ a $5^{a}$ série do ensino fundamental (Relatório de pesquisa. São Cristovão-SE: Departamento de Educação, UFS, 2006); organizou com SANTOS, Dayse Maria dos; FREIRE, José Marcos Monteiro. Universidade além da sala de aula: extensão universitária desenvolvimento local e cidadania (São Cristovão: Editora da UFS, 2006). Pesquisa em andamento: "Estudo comparativo de indicadores de sucesso ou fracasso de jovens na conquista de uma vaga na universidade pública”.E-mail: vcharlot@terra.com.br

Recebido em dezembro de 2006 Aprovado em setembro de 2007 
Veleida Anahi da Silva

\section{Relação com o saber na} aprendizagem matemática: uma contribuição para a reflexão didática sobre as práticas educativas

Esse artigo refere-se a uma pesquisa realizada em Sergipe, em 2004-2006, junto a 362 alunos da $1^{\mathrm{a}}$ à $5^{\mathrm{a}}$ série do ensino fundamental. São objetivos compreender os fundamentos e processos da relação dos alunos com a aprendizagem matemática e verificar a importância da pesquisa de campo para desvelar as representações e os saberes ocultos no processo ensino-aprendizagem. Do ponto de vista metodológico, os dados foram recolhidos por meio de um questionário com 14 perguntas abertas. A análise, além da abordagem geral, introduz um duplo ponto de vista comparativo: entre os dois sexos e entre os níveis de escolaridade. O referencial teórico repousa nas pesquisas de Bernard Charlot e de Claudine Blanchard-Laville sobre a relação com o saber. Nos resultados destaca-se que os alunos se relacionam com objetos e práticas cotidianas, como contar o dinheiro, mais do que com objetos especificamente matemáticos. Esses resultados oferecem bons indicadores para uma reflexão na óptica da didática.

Palavras-chave: relação com o saber; ensino da matemática; didática; práticas educativas 


\section{Relation with knowledge in}

mathematics learning: a

contribution to the didactic reflection on educational practices

This paper refers to a research carried out in the state of Sergipe between 2004 and 2006, with 362 pupils from $1^{\text {st }}$ to $5^{\text {th }}$ grade of elementary school. The objectives are to comprehend the bases and processes of the pupils' relation to mathematics learning and verify the importance of fieldwork in revealing the representations and the hidden knowledge in the teaching/ learning process. From the methodological point of view, the data were gathered by means of a questionnaire with 14 open questions. In addition to the general approach, the analysis introduces a double comparative point of view: between the two sexes and different levels of schooling. Research by Bernard Charlot and Claudine Blanchard-
Laville on the relation with knowledge provides the theoretical framework. The results suggest that pupils have a better relationship with everyday objects and practices, like counting money, than with specifically mathematical objects. These results offer good indicators for a reflection from the perspective of didactics.

Key words: relation with knowledge; teaching of mathematics; didactics; educational practices

Relación con el saber en el aprendizaje de matemáticas: una contribución para la reflexión didáctica sobre las prácticas de educación

Este artículo se refiere a una encuesta realizada en Sergipe, en 2004-2006, junto a 362 alumnos del 1er. al 5to. año del primario. Son objetivos comprender los fundamentos y procesos de la relación de los alumnos con el aprendizaje de matemática y comprobar la importancia de la encuesta de campo para descubrir las representaciones y el saber oculto en el proceso enseñanzaaprendizaje. Del punto de vista metodológico, los datos fueron recogidos a través de un cuestionario con 14 preguntas abiertas. El análisis, además de un abordaje general, introduce un doble punto de vista comparativo: entre los dos sexos y entre los niveles de escolaridad. El referencial teórico reposa en las pesquisas de Bernard Charlot y de Claudine Blanchard-Laville sobre la relación con el saber. En los resultados se destaca que los alumnos se relacionan con objetos y experiencias cotidianas, como contar el dinero, más de lo que con objetos especificamente matemáticos. Estos resultados ofrecen buenos indicadores para una reflexión en la óptica de la didáctica.

Palabras claves: relación con el saber; enseñanza de la matemática; didáctica; experiencias educativas 